Original Article

\title{
Analisis Pelaksanaan Program Prolanis Di Puskesmas Rawat Inap Biha Kabupaten Pesisir Barat
}

\author{
Analysis of the Implementation of the Prolanis Program at the Biha Inpatient Health Center, \\ Pesisir Barat Regency
}

\author{
Lena Wedyarti*, Bambang Setiaji, Ferizal Masra \\ Prodi Magister Kesehatan Masyarakat, Universitas Mitra Indonesia
}

(wedyartilena@gmail.com,081210228768)

\begin{abstract}
ABSTRAK
Hipertensi dan diabetes mellitus merupakan Penyakit Tidak Menular (PTM) yang paling banyak mendapat perhatian dunia. Hipertensi dan diabetes mellitus dijuluki sebagai silent killer karena sering muncul tanpa keluhan, akibatnya banyak penderita terlambat untuk mendapatkan penanganan yang memadai. Tujuan dalam penelitian untuk menganalisis pelaksanaan prolanis di Puskesmas Biha. Penelitian ini menggunakan metode kualitatif menggunakan metode pengumpulan data survey bersifat cross sectional dengan jenis rancangan deskriptif. Informan berjumlah 8 orang dan instrumen yaitu pedoman wawancara mendalam, daftar tilik observasi dan daftar tilik telaah dokumen. Hasil penelitian menunjukkan bahwa pelaksanaan prolanis masih belum maksimal, hal ini ditandai dengan pelaksanaan edukasi belum maksimal, masih banyak peserta yang kurang pengetahuan tentang penyakitnya. Saran kepada puskesmas agar petugas membuat jadwal pasti pelaksanaan edukasi tentang hipertensi dan dm serta membuat inovasi agar peserta dapat antusias mengikuti kegiatan tersebut.
\end{abstract}

Kata kunci : Prolanis, Hipertensi, Diabetes mellitus, BPJS, Puskesmas

\section{ABSTRACT}

Hypertension and diabetes mellitus are non-communicable diseases (NCDs) that get the most attention in the world. Hypertension and diabetes mellitus are dubbed the silent killers because they often appear without complaints, as a result, many sufferers are late to get adequate treatment. The purpose of the study was to analyze the implementation of prolanis at the Biha Health Center. This study uses a qualitative method using survey data collection methods are cross sectional with a descriptive type of design. There were 8 informants and the instruments were in-depth interview guidelines, observation checklists and document review checklists. The results showed that the implementation of prolanis was still not optimal, this was indicated by the implementation of education not being maximized, there were still many participants who lacked knowledge about their disease. Suggestions to the puskesmas that the officers make a definite schedule for the implementation of education about hypertension and DM and make innovations so that participants can be enthusiastic about participating in these activities.

Keywords: Prolanis, Hypertension, Diabetes mellitus, BPJS, Puskesmas

https://doi.org/10.33860/jik.v15i3.505

(C) 2021 by the authors. Submitted for possible open access publication under the terms and conditions of the Creative Commons Attribution (CC BY SA) license (https://creativecommons.org/licenses/by-sa/4.0/). 


\section{PENDAHULUAN}

Hipertensi dan diabetes mellitus merupakan Penyakit Tidak Menular (PTM) yang paling banyak mendapat perhatian dunia. Hipertensi dan diabetes mellitus dijuluki sebagai silent killer karena sering muncul tanpa keluhan, akibatnya banyak penderita terlambat untuk mendapatkan penanganan yang memadai. Menurut Kemenkes RI, tahun 2017 hanya $36,8 \%$ penderita hipertensi yang tercakup oleh tenaga kesehatan sementara penderita diabetes mellitus hanya $30,4 \%{ }^{1}$. Menurut laporan WHO pada tahun 2018, diabetes mellitus telah menyebabkan $6 \%$ kematian di Indonesia dan lebih dari $60 \%$ penderita yang berjenis kelamin laki-laki dan $40 \%$ perempuan meninggal sebelum berusia 70 tahun ${ }^{2}$. berdasarkan hasil Riset Kesehatan Dasar (Riskesdas) tahun 2013 menunjukan bahwa prevalensi penderita hipertensi mencapai $25,8 \%$, kemudian naik menjadi $34,1 \%$ pada tahun $2018^{1}$. berdasarkan hasil Riset Kesehatan Dasar (Riskesdas) tahun 2013 menunjukan bahwa prevalensi penderita hipertensi mencapai $25,8 \%$, kemudian naik menjadi $34,1 \%$ pada tahun $2018^{1}$. Angka kejadian diabetes mellitus di dunia juga terus meningkat, tahun 2014 mencapai 422 juta naik menjadi 425 juta tahun 2017. Saat ini, jumlah penderita diabetes mellitus di Indonesia adalah tertinggi kedua di dunia, meningkat dari tahun 2015 yang berada diposisi ketujuh. Posisi pertama diduduki oleh China dengan jumlah 120.907 .995 penderita, disusul Indonesia dengan jumlah 10.276.100 penderita, negara ketiga adalah Jepang dengan jumlah 8.343.288 penderita $^{3}$. Prevalensi diabetes mellitus di Provinsi Lampung berdasarkan Riskesdas tahun 2013 adalah 1.8\%, kemudian naik menjadi 2\%tahun 2018. Di Provinsi Lampung, jumlah penderita diabetes mellitus mencapai 31.462 orang.

Dalam rangka pengendalian penyakit hipertensi dan diabetes mellitus di Indonesia, pemerintah membuat suatu program promotif dan preventif yang diharapkan mampu meningkatkan kualitas hidup penderita, program tersebut diberi nama Program Pengelolaan Penyakit Kronis (Prolanis). Pengimplementasian Prolanis disinergikan dengan program pengendalian penyakit tidak menular di FKTP ${ }^{4}$. Beberapa aktivitas dalam Prolanis yaitu: konsultasi medis, edukasi kelompok, reminder melalui SMS gateway, home visit, aktivitas fisik (senam Prolanis), pemantauan status kesehatan peserta Prolanis, dan pelayanan obat ${ }^{4}$. Prolanis di Puskesmas Rawat Inap Biha telah berjalan sejak tahun 2017 dan berdasarkan data profil kesehatan Puskesmas Rawat Inap Biha, hipertensi dan diabetes mellitus masih menjadi penyakit dengan angka kejadian tertinggi di Puskesmas Biha. Penyakit hipertensi berada di posisi pertama dan diabetes mellitus di posisi ketigapelaksanaan prolanis yang berjalan di Puskesmas Biha hanya pemantauan kesehatan yang dilakukan dengan program Posbindu, home visit dan aktivitas senam.

Berdasarkan latar belakang diatas, penelitian ini bertujuan bertujuan untuk mengetahui bagaimana implementasi Program Pengelolaan Penyakit Kronis di Puskesmas Biha Tahun 2021.

\section{METODE PENELITIAN}

Jenis penelitian ini adalah kualitatif deskriptif. Penelitian ini dilaksanakan di Puskesmas Rawat Inap Biha Kabupaten Pesisir Barat pada bulan Juli 2021. Desain studi penelitian kualitatif dengan metode pengambilan data survey. Pemilihan metode penelitian kualitatif dilakukan karena obyek yang diteliti harus digali secara mendalam agar dapat memberikan jawaban yang dicari atas permasalahan yang diteliti.

Teknik pengumpulan data meliputi data primer melalui wawancara mendalam dan sekunder melalui dokumen-dokumen. Informan penelitian diambil 8 orang yang terdiri dari Kepala Puskesmas (1 orang), Dokter (1 orang), Penanggung Jawab Prolanis (1 orang), BPJS Kesehatan (1 orang), Perawat BP (1 orang), Petugas Pcare (1 Orang), Petugas Lab (1 orang) dan Peserta Prolanis (1 orang).

Dalam penelitian ini faktor input yang terdiri dari sumber daya manusia (SDM), sarana dan prasarana serta biaya operasional, sedangkan proses terdiri dari pelaksanaan 7 aktivitas prolanis. Faktor output yaitu untuk mengetahui tingkat keberhasilan pelaksanaan Prolanis di Puskesmas Rawat Inap Biha.

\section{HASIL}

\section{Karakteristik Puskesmas Rawat Inap Biha}

Peraturan Menteri Kesehatan Republik Indonesia No. 75 Tahun 2014 menyatakan bahwa Puskesmas adalah fasilitas kesehatan masyarakat yang menyelenggarakan upaya kesehatan masyarakat dan perseorangan tingkat 
pertama dengan lebih mengutamakan upaya promotif dan preventif untuk mencapai derajat kesehatan masyarakat yang setinggi-tingginya di wilayah kerjanya ${ }^{5}$. Salah satu Puskesmas yang terdapat di Wilayah Kabupaten Pesisir Barat adalah UPTD Puskesmas Rawat Inap Biha. Wilayah kerja UPTD Puskesmas Rawat Inap Biha mencakup seluruh wilayah Kecamatan Pesisir Selatan, dengan luas wilayah 409, $2 \mathrm{~km} 2$. Ibu kota kecamatannya adalah Biha, berjarak sekitar $26 \mathrm{~km}$ dari ibu kota Kabupaten pesisir Barat dan $222 \mathrm{~km}$ dari ibukota Provinsi Lampung melalui jalan lintas barat. Wilayah kerja Puskesmas Rawat Inap Biha terdiri dari 15 pekon/desa. Jumlah sumber daya manusia Puskesmas Rawat Inap Biha sebanyak 100 orang.

\section{Karakteristik Informan}

Para informan penelitian ini adalah : Kepala Puskesmas, Pihak BPJS, Penanggung Jawab Prolanis, Dokter Puskesmas, Perawat/Bidan Balai Pengobatan dan Masyarakat/peserta Prolanis.

\section{Input Pelaksanaan Prolanis Sumber Daya Manusia}

Tim prolanis terpadu belum dibentuk, hanya ada penanggung jawab program terkait pelaksanaan Prolanis. Kemudian, petugas tersebut belum mendapatakan pelatihan dari BPJS terkait pelaksanaan Prolanis, sehingga penanngung jawab program mencari informasi tentang prolanis melalui media sosial dan internet (informan 1,2,3).

Untuk sumber daya manusia terkait pelaksanaan prolanis di Puskesmas Biha terdiri dari dokter, perawat/bidan, penanggung jawab prolanis dan tenaga kesehatan lainnya (informan 4,5).

Hasil observasi bahwa tidak terdapat surat keputusan (SK) tentang penetapan tim prolanis terpadu Puskesmas Biha. Namun, terdapat surat perintah tugas bagi bidan yang dipilih oleh Kepala Puskesmas sebagai penanngung jawab Prolanis di Puskesmas Biha. Selanjutnya, dalam hal pelatihan yang diberikan oleh BPJS bahwa penanggung jawab prolanis belum mengikuti pelatihan dan pihak BPJS belum mengadakan pelatihan terkait prolanis. Namun, untuk memfasilitasi hal tersebut, pihak BPJS melakukan mentoring kepada dokter dan penangung jawab prolanis.

\section{Sarana dan Prasarana}

Sarana dan prasarana terkait pelaksanaan prolanis yang terdapat di Puskesmas Biha, antara lain : alat pengukur tekanan darah, alat pengukur gula darah, sound system untuk kegiatan senam prolanis semua dalam keadaan baik. Selain itu, puskesmas Biha memiliki gedung, lapangan, laboratorium, ruang konsultasi untuk mendukung pelaksanaan kegiatan prolanis.

\section{Biaya Operasional}

Biaya operasional pelaksanaan program prolanis bersumber dari dana Jaminan Kesehatan Nasional (JKN) dari BPJS Kesehatan dan dibayarkan ke FKTP dengan sistem klaim dan dibayarkan melalui sistem kapitasi. Dana tersebut digunakan untuk pelaksanaan prolanis. Dari hasil wawancara bahwa dana tersebut digunakan untuk membeli konsumsi, seperti snack, buah-buahan dan minuman serta akomodasi instuktur untuk kegiatan senam. Dana tersebut dikelola oleh pengelola prolanis sesuai dengan ketentuan yang berlaku dan para peserta prolanis tidak dikenakan biaya selama mengikuti kegiatan prolanis tersebut dan para petugas tidak mendapat jasa dari dana tersebut karena jasa petugas dimasukan ke dalam kapitasi.

\section{Proses Pelaksanaan Prolanis Konsultasi Medis}

Pelaksanaan kegiatan konsultasi medis dilakukan dengan dokter dan tim yang sudah ditentukan (informan 2). Namun, tidak dijelaskan secara rinci tentang waktu pelaksanaan konsultasi tersebut. Hasil wawancara dengan Informan 2 bahwa pelaksanaan konsultasi medis dapat dilakukan dengan whatsapp. Jadi, peserta prolanis dapat menggunakan whatsapp untuk menyampaikan keluhan yang dirasakan. Namun, hasil observasi didapatkan bahwa peserta prolanis banyak yang sudah berusia lansia dan tidak dapat menggunakan whatsapp. Sehingga, pelaksanaan konsultasi medis dibantu oleh keluarga peserta.

\section{Edukasi Kelompok}

Kegiatan edukasi kelompok di Puskesmas Biha sudah berjalan sebanyak satu kali setiap bulan (Informan 1, 2, 3, 4). Namun, karena saat ini sedang pandemi, maka kegiatan edukasi kelompok dilakukan setiap 3 bulan sekali dengan protokol kesehatan, seperti peserta 
dibatasi, menjaga jarak dan lain sebagainya (Informan 3). Hasil observasi didapatkan bahwa kegiatan edukasi kelompok belum berjalan secara optimal dan efektif, karena tidak terdapat jadwal tetap untuk kegiatan edukasi kelompok. Kemudian, selama pandemi ini kegiatan tersebut dilaksanakan selama 3 bulan sekali. Hal ini menyebabkan kegiatan edukasi kelompok di Puskesmas Biha berjalan kurang maksimal.

\section{Pemantauan Status Kesehatan}

Pelaksanaan pemantauan kesehatan dilakukan setiap satu bulan sekali yang meliputi : cek tekanan darah, timbang berat badan dan cek kadar gula darah. Pelaksanaan kegiatan pemantauan status kesehatan dilakukan dengan peserta bertemu dengan dokter. Kemudian, diberikan resep obat jika diperlukan. Hasil pertemuan antara dokter dan peserta didokumentasikan ke dalam rekam medis. Hasil penelitian didapatkan bahwa pelaksanaan di lapangan kegiatan pemantauan status kesehatan prolanis dilakukan dengan baik dan bersamaan dengan kegiatan posbindu yang ada di Puskesmas. Pada saat kegiatan Posbindu di salah satu pekon/desa, petugas Prolanis melakukan pemantauan kesehatan kepada peserta prolanis yang bertempat tinggal di Pekon tersebut. Tujuannya untuk memudahkan peserta yang memiliki akses yang jauh untuk mendapatakan pelayanan kesehatan.

\section{Pelayanan Obat}

Pelayanan obat prolanis diberikan kepada peserta Prolanis sesuai indikasi yang ada (Informan 4). Pelayanan obat hanya dilakukan di Puskesmas dengan dilakukan konsultasi medis dan pemantauan status kesehatan terlebih dahulu, kemudian dokter akan memberikan resep obat yang dapat di ambil di apotek (Informan 2,3). Resep diberikan sesuai indikasi yang dirasakan oleh peserta. Setelah itu, resep obat tersebut diinput oleh petugas Pcare ke aplikasi Pcare secara online (Informan 7). Hasil pengamatan di lapangan, bahwa pemberian obat dapat dilakukan bersama dengan Program Posbindu dan home visit. Hasil wawancara dengan peserta prolanis (informan 8) bahwa obat diminum ketika peserta merasa keluhan darah tinggi atau hipertensi.

\section{Aktivitas Senam}

Pelaksanaan kegiatan senam prolanis di Puskesmas Biha dilaksanakan untuk penderita hipertensi dan diabetes melitus yang dilaksanakan setiap seminggu sekali. Namun, karena kondisi sedang pandemi, maka senam prolanis dilakukan setiap sebulan sekali.

\section{Home Visit}

Kegiatan home visit prolanis di Puskesmas Biha dilakukan setiap bulan dengan jumlah peserta yang dilakukan home visit ditentukan oleh penanggung jawab program atau sesuai dengan kebutuhan dan indikasi yang muncul. Kegiatan ini dilakukan dalam rangka memonitor status kesehatan peserta dan memfasilitasi peserta yang mengalami kesulitan untuk hadir dalam kegiatan prolanis. Selain itu, kegiatan ini dilakukan untuk memenuhi target yang telah ditetapkan oleh BPJS (Informan 3).

\section{Reminder}

Pelaksanaan kegiatan reminder kurang berjalan dengan efektif dan optimal. Hal ini ditandai dengan keterbatasan petugas dalam melakukan reminder kepada peserta dikarenakan banyaknya program yang dilaksanakan. Dengan kata lain, petugas prolanis memegang rangkap program, sehingga pelaksanaan program reminder kurang optimal.

\section{Output Pelaksanaan Prolanis}

Output yang dihasilkan adalah semua peserta prolanis dapat terkendali dan beraktivitas dengan baik dalam kehidupan sehari-hari, sehingga dapat mengurangi resiko kesakitan dari peserta, mendorong kemandirian peserta, mengendalikan biaya pelayanan kesehatan jangka panjang, meningkatkan kepuasan peserta dan status kesehatan peserta Prolanis terkendali.

\section{PEMBAHASAN}

\section{Input}

Input pelaksanaan prolanis di Puskesmas Biha secara umum sudah baik. Sumber daya manusia yang dimiliki oleh Puskesmas Biha sudah cukup memadai walaupun belum adanya SK penetapan tim prolanis terpadu. Namun, Kepala Puskesmas sudah mengeluarkan surat perintah tugas kepada staf yang dipilih. Petugas prolanis di Puskesmas Biha terdiri dari : penanggung jawab prolanis, dokter, perawat/bidan, petugas lab, petugas Pcare dan pelayanan obat. Tidak ada ketentuan khusus dari BPJS terkait jumlah petugas yang ikut dalam kegiatan prolanis ${ }^{4}$. 
Selanjutnya, tim tersebut masih belum mendapatkan pelatihan tentang pelaksanaan Prolanis, sehingga pelaksanaan prolanis masih belum sesuai dengan ketentuan yang ada. Tetapi, walaupun belum mendapatkan pelatihan tentang prolanis, tim tersebut secara mandiri mencari sumber literatur untuk menambah pengetahuan dengan cara mencari sumber literatur melalui media sosial dan internet. Hal ini, sejalan dengan penelitian Lisa yang menyebutkan bahwa bentuk pengembangan kapasitas petugas kesehatan yang terlibat dalam pengelolaan kegiatan Prolanis yang diberikan BPJS Kesehatan adalah hanya berupa mentoring penatalaksanaan hipertensi dan diabetes mellitus terhadap dokter pengelola Prolanis. Mentoring ini diadakan dengan menghadirkan dokter spesialis dan diadakan sekali setahun ${ }^{6}$. Pengembangan SDM sangat diperlukan karena memiliki aspek yang penting bagi peningkatan produktivitas SDM dan juga memiliki tujuan-tujuan tertentu yang pastinya harus dicapai demi kemajuan suatu perusahaan atau organisasi pelayanan sosial ${ }^{7}$.

Sarana dan prasarana yang terdapat di Puskesmas Biha tahun 2021, antara lain ruang dokter/konsultasi digunakan untuk tempat pelaksanaan pemantauan status kesehatan maupun konsultasi peserta prolanis, ruangan tersebut dilengkapi dengan meja, kursi, tempat tidur pasien, wastafel, stetoskop dan tensimeter serta alat timbang berat badan. Menurut penelitian Sarmaulina, dkk yang menyebutkan bahwa fasilitas yang menunjang kegiatan Prolanis yaitu tempat penyuluhan, media penyuluhan, tempat senam, sound system, layar LCD dan proyektor, serta alat-alat medis untuk melakukan pemeriksaan peserta prolanis ${ }^{8}$. Hal ini sejalan dengan penelitian yang dilakukan oleh Sitompul, dkk yang menyebutkan bahwa sarana prasarana yang disediakan untuk menunjang kegiatan prolanis disesuaikan dengan kemampuan dan ketersedian sarana di dokter keluarga, dan layak atau tidak layak dari BPJS Kesehatan ${ }^{8}$. Dalam buku pedoman Prolanis yang dikeluarkan BPJS Kesehatan, tidak disebutkan secara rinci apa saja hal yang menjadi sarana dalam pelaksanaan program ${ }^{9}$.

Pembagian dana operasional di Puskesmas Biha, bahwa untuk jasa para petugas dibayarkan melalui sistem kapitasi dan untuk pelaksanaan kegiatan prolanis menggunakan dana non kapitasi. Sitompul menyebutkan bahwa pembiayaan kegiatan Prolanis yang mencakup edukasi/konsultasi medis, reminder (sms gateway), aktivitas klub, pemantauan kesehatan, home visit, mentoringsudah diatur di dalam PMK No. 59 Tahun 2014 tentang Standar Tarif Pelayanan Kesehatan dalam Penyelenggaraan Program Jaminan Kesehatan yaitu mengenai tarif pelayanan kesehatan pada FKTP meliputi tarif kapitasi dan tarif non kapitasi $^{5}$. Hal ini sesuai dengan Hal ini sejalan dengan penelitian yang dilakukan oleh Murni.dkk yang dilakukan di Puskesmas Kedai Durian Medan Johor bahwa pembagian dana untuk kegiatan Prolanis ada dua macam,ada yang dari dana kapitasi dan ada dana yang dari non kapitasi. Dana yang digunakan untuk kegiatan edukasi medis dan senam prolanis didapatkan dari dana non kapitasi. Jumlah dana yang di dapat setiap minggunya sebesar Rp. 360.000 untuk honor instruktur senam dan snack peserta prolanis, sedangkan danayang diperlukan untuk kegiatan pemantauan status kesehatan, pelayanan obat dan home visit didapatkan dari dana kapitasi dan untuk kegiatan reminder SMS gateway tidak ada karena kegiatan ini sudah diganti dengan menggunakan Whatsapp, sehingga tidak perlu menggunakan dana ${ }^{9}$.

\section{Proses}

Konsultasi medis adalah kegiatan konsultasi yang dilakukan oleh dokter dan peserta untuk menunjang kepuasan peserta dalam bertanya tentang keluhan yang sedang dirasakannya. Berdasarakan buku pedoman pelaksanaan prolanis bahwa jadwal konsultasi medis seharusnya disepakati bersama antara peserta dan dokter ${ }^{4}$. Hal ini sejalan dengan penelitian yang dilakukan oleh Lisa.dkk bahwa beberapa peserta Prolanis di Puskesmas Parsoburan yang menjadi informan dalam penelitian ini mengaku bahwa mereka merasa puas dengan pelayanan konsultasi medis peserta Prolanis yang diberikan oleh Puskesmas Parsoburan, hal ini dikarenakan mereka diberikan kebebasan untuk berkonsultasi dengan dokter pengelola Prolanis dan dokter juga memberikan respon yang baik dalam menjawab pertanyaan peserta serta menunjukkan sikap ramah saat berkomunikasi dengan peserta Prolanis ${ }^{6}$. Hal ini selaras dengan penelitian yang dilakukan oleh Wahyuni.dkk bahwa semakin baik komunikasi antara dokter dengan pasien, maka semakin mempengaruhi tingginya kepuasan pasien dalam pelayanan ${ }^{10}$.

Edukasi kelompok merupakan sebuah program yang bersifat promotif dan preventif 
maka peningkatan pengetahuan peserta Prolanis mengenai kesehatan adalah salah satu sasaran dalam pengimplementasian Prolanis di FKTP yang dapat diwujudkan melalui kegiatan edukasi kelompok. Edukasi kelompok Prolanis bertujuan menambah pengetahuan kesehatan peserta, dengan demikian diharapkan mampu memulihkan penyakitnya dan mencegah timbulnya kembali penyakit, sehingga peserta terhindar dari komplikasi penyakit yang lebih berat dan mampu mencapai kualitas hidup secara optimal ${ }^{6}$. Kepastian jadwal pelaksanaan kegiatan edukasi kelompok merupakan hal penting karena mempengaruhi kehadiran peserta dan jika tidak terdapat pemberitahuan tentang perubahan jadwal, maka peserta akan sulit untuk mengikuti kegiatan. Kejelasan informasi pelayanan dan tingkat kesesuaian waktu dapat mempengaruhi besarnya jumlah peserta dalam memanfaatkan sebuah pelayanan ${ }^{11}$. Penelitian Machmud, Rizanda et al., (2014) yang menyatkan bahwa kualitas pelayanan sudah memenuhi harapan pasien prolanis, dari segi fasilitas fisik dan cara komunikasi petugas ${ }^{12}$.

Pemantauan status kesehatan merupakan salah satu kegiatan prolanis yang dilakukan untuk mengetahui perkembangan dari status kesehatan peserta untuk mengontrol riwayat pemeriksaan kesehatan serta mencegah agar tidak terjadi komplikasi atau penyakit lanjutan ${ }^{4}$. Kegiatan pemantuan status kesehatan dilakukan setiap kegiatan kelompok maupun home visit. Hal ini sejalan dengan penelitian Sitompul yang mengatakan bahwa kegiatan pemantauan status kesehatan yang dilaksanakan meliputi pemeriksanaan tekanan darah, gula darah dan berat badan ${ }^{8}$.

Peresepan obat peserta Prolanis yang dilakukan berdasarkan formularium nasional. Setiap bulan peserta Prolanis berhak mendapatkan jatah obat yang harus dikonsumsi selama satu bulan penuh ${ }^{6}$. Dengan tersedianya aplikasi P-care, maka peserta Prolanis tidak akan mendapatkan obat dengan jenis yang sama dari rumah sakit, dengan demikian pelayanan obat peserta Prolanis lebih efektif dan efisien ${ }^{6}$. Kondisi peserta Prolanis yang meminum obat jika hanya sudah merasakan keluhan, menunjukkan bahwa belum semua peserta Prolanis memiliki pemahaman tentang karakteristik penyakit hipertensi dan diabetes yang merupakan penyakit yang sering kali muncul tanpa keluhan, namun sering sekali menyerang secara tiba-tiba bahkan menyebabkan komplikasi yang lebih berat ${ }^{6}$. Hal ini menunjukkan bahwa peserta prolanis belum memiliki pengetahuan yang cukup bahwa tingkat pengetahuan peserta dapat mempengaruhi kepatuhan peserta prolanis dalam pengobatan, semakin tinggi tingkat pengetahuan, maka semakin tinggi kepatuhan dalam meminum obat ${ }^{11}$. Hal ini didukung penelitian Primahuda dan Sujianto (2016) menyebutkan ada hubungan yang signifikan antara kepatuhan mengikuti prolanis dengan stabilitas gula darah dengan ditunjukkannya semakin tinggi tingkat kepatuhan maka semakin baik stabilitas gula darahnya ${ }^{13}$. Harniati dkk (2018) yang menjelaskan ketidakpatuhan mengikuti kegiatan prolanis ada hubungan antara pemahaman tentang instruksi, kualitas interaksi, dukungan keluarga, keyakinan, sikap dengan ketidakpatuhan mengikuti kegiatan prolanis. kualitas interaksi dan sikap merupakan faktor yang paling dominan dalam hubunganya dengan ketidakpatuhan mengikuti kegiatan prolanis ${ }^{14}$.

Kegiatan home visit yang dilakukan petugas prolanis di Puskesmas Biha selalu dilakukan setiap bulan kepada peserta yang tidak dapat mengikuti kegiatan prolanis atau peserta yang mempunyai keterbatasan dalam menjangkau pelaksanaan prolanis. Hal ini selaras dengan penelitian Sitompul.dkk mengatakan bahwa home visit bertujuan untuk mengedukasi keluarga peserta agar pengobatan bisa diawasi dan berjalan dengan baik, sehingga berdampak langsung terhadap kondisi peserta melalui home visit ${ }^{8}$. Begitu pula juga, dalam penelitian Meiriana dkk, kegiatan home visit dilakukan dengan kunjungan ke rumah peserta prolanis minimal lima kali dalam sebulan. Kegiatan home visit dilakukan terhadap peserta yang tidak hadir selama pelaksanaan home visit 3 bulan berturut-turut tanpa ada penjelasan, pasien yang kondisinya tidak dapat terkontrol ke FKTP dan pasien yang baru pulang setelah menjalani rawat inap. Penelitian Anita Meiriana dkk (2019) menunjukkan bahwa Puskesmas membatasi kepesertaan prolanis karena keraguan dalam mengendalikan untuk rutin datang setiap bulannya.Puskesmas mengadakan kegiatan prolanis yang tidak rutin dilaksanakan yaitu senam dan home visit ${ }^{15}$.

Menumpuknya beberapa tanggung jawab dalam melaksanakan beberapa kegiatan Prolanis pada satu petugas tertentu menunjukkan bahwa pengorganisasian petugas Prolanis dalam hal pembagian kerja diantara 
petugas Prolanis di Puskesmas Parsoburan kurang maksimal sehingga terjadi overlapping tugas dan tanggung jawab pada satu petugas yang menyebabkan pelaksanaan kegiatan reminder Prolanis kurang maksimal ${ }^{6}$.

Penelitian lainnya menunjukkan bahwa hambatan Prolanis yaitu beberapa peserta Prolanis sering tidak hadir dalam kegiatan Prolanis, para penderita diabetes militus tidak terjaring secara maksimal, kurangnya koordinasi dan kerjasama antara faskes 1 dan faskes ${ }^{16}$.

\section{Output}

Output yang dihasilkan adalah semua peserta prolanis dapat terkendali dan beraktivitas dengan baik dalam kehidupan sehari-hari, sehingga dapat mengurangi resiko kesakitan dari peserta, mendorong kemandirian peserta, mengendalikan biaya pelayanan kesehatan jangka panjang, meningkatkan kepuasan peserta dan Status kesehatan peserta Prolanis terkendali. Hal ini sejalan dengan penelitian yang dilakukan oleh Lisa bahwa output yang diharapkan dari pelaksanaan prolanis adalah agar kesehatan setiap peserta Prolanis terkontrol, sehingga dapat terhindar dari komplikasi penyakit ${ }^{6}$.

\section{KESIMPULAN DAN SARAN}

Pelaksanaan program prolanis di Puskesmas Biha sudah baik, meskipun masih ada kegiatan yang belum optimal yaitu edukasi kelompok dan reminder. Saran dalam penelitian ini adalah embuat perencanaan edukasi kelompok peserta Prolanis mengenai jadwal kegiatan, narasumber, materi yang diberikan dan menilai perubahan pada peserta untuk kemudian menentukan strategi dan target capaian edukasi berikutnya, sehingga peserta dapat meningkat pengetahuan dan wawasan dan patuh dalam meminum obat. Memberdayakan peserta Prolanis yang aktif untuk menjadi kader yang memotivasi sesama peserta agar turut aktif dalam kegaiatan Prolanis.

\section{DAFTAR PUSTAKA}

1. Kemenkes RI. Hasil Utama Riskesdas 2018. 2018.

2. World Health Organization. Diabetes. 2018.

3. International Diabetes Federation. International Diabetes Federation. 2018.

4. Badan Penyelenggara Jaminan Sosial Kesehatan. Panduan Praktis Prolanis. 2014.
5. Permenkes RI. Peraturan Menteri Kesehatan RI No. 75 Tahun 2014 tentang Pusat Kesehatan Masyarakat. 2014.

6. Sinulingga L. Analisis Pelaksanaan Program Pengelolaan Penyakit Kronis (Prolanis) Di Puskesmas Biha Sumatera Utara Tahun 2019. 2019.

7. Bariqi MD. Pelatihan Dan Pengembangan Sumber Daya Manusia. JSMB Jurnal Studi Manajemen dan Bisnis. 2018;5(2):64-9.

8. Sitompul S, Suryawati C, Wigati PA. Analisis Pelaksanaan Program Pengelolaan Penyakit Kronis (Prolanis) Bpjs Kesehatan Pada Dokter Keluarga Di Kabupaten Pekalongan Tahun 2016. Jurnal Kesehatan Masyarakat Universitas Diponegoro. 2016;4(4).

9. Nasution MN. Implementasi Program Pengelolaan Penyakit Kronis (PROLANIS) Di Puskesmas Kedai Durian Medan Johor Tahun 2018. Universitas Sumatera Utara; 2018.

10. Wahyuni T, Yanis A, Erly. Hubungan komunikasi dokter-pasien terhadap kepuasan pasien berobat di Polikilini RSUP. Dr. Djamil Padang. Jurnal Fakultas Kedokteran UNAND. 2013;2(5):175-7.

11. Firdha A, Arifa C. Pengaruh Informasi Pelayanan Prolanis dan Kesesuaian Waktu terhadap Pemanfaatan Prolanis di Pusat Layanan Kesehatan Unair. Jurnal Administrasi Kesehatan Indonesia. 2018;6(2):95-102.

12. Machmud R, Maryeti M, Isnati I, Abdiana A. Survei Kepuasan dan Manajemen Keluhan Pasien Diabetes Melitus terhadap Pelayanan Kesehatan Prolanis Askes di Rumah Sakit Pemerintah Propinsi Sumatera Barat. Jurnal Kebijakan Kesehatan Indonesia : JKKI. 2014 Sep 1;3(3):164-71.

13. Primahuda A, Sujianto U. Hubungan Antara Kepatuhan Mengikuti Program Pengelolaan Penyakit Kronis (PROLANIS) BPJS dengan Stabilitas Gula Darah pada Penderita Diabetes Melitus di Puskesmas Babat Kabupaten Lamongan [Internet] [other]. [Semarang]: Faculty of Medicine; 2016 [cited 2021 Nov 30]. Available from: http://eprints.undip.ac.id/49908/

14. Harniati A, Suriah S, Amqam $\mathrm{H}$. Ketidakpatuhan Peserta Bpjs Kesehatan Mengikuti Kegiatan Prolanis Di Puskesmasrangas Kabupaten Mamuju. Jurnal Kesehatan Masyarakat Maritim. 2018;1(1):16.

15. Meiriana A, Trisnantoro L, Padmawati RS. Implementation of Chronic Program (Prolanis) Program in Hypertension Disease in Puskesmas Jetis Kota Yogyakarta. Jurnal Kebijakan Kesehatan Indonesia: JKKI. 2019;8(2):51-8. 
16. Susanti I, Hartati CS, Putro G. Kualitas Pelayanan Program Pengelolaan Penyakit Kronis (Prolanis) Pasien Diabetes Militus Di

Klinik Prima Medika Sidoarjo. Jurnal Manajerial Bisnis. 2018 Aug 1;1(03):1-14. 